\title{
A Study on the Application of Euphemism From the Perspective of Politeness Principle
}

\author{
Hui He \\ School of Foreign Languages, Zhengzhou University of Industrial Technology, Zhengzhou 451100, \\ China
}

1456108581@qq.com

Keywords: euphemism, social functions, politeness principle, Leech's maxims.

\begin{abstract}
Euphemism, also called embellishing language, is a common phenomenon in language, society and culture. It is used as a mirror, reflecting moral concept, values, and aesthetic conceptions in a sense. Euphemism plays an important role in our daily life. It is used as lube in interpersonal communication that helps avoid hurting the others' feeling. It oils the human relationship in communication and helps to save face of communicators. If people make full use of euphemism, it can accelerate and facilitate interpersonal communication. From the angle of pragmatics and culture, and based on the theory of the Politeness Principle, this thesis studies the extensive use of English and Chinese euphemisms in every social field by analyzing examples. This thesis mainly analyzes English and Chinese euphemisms reflect the six maximums of politeness principle. Besides, Chinese and English euphemisms under the guidance of politeness principle have widely used in the fields of communication in culture, political affairs and economical activities. From the analysis, it is found that only when euphemism is properly used, can reflect its value.
\end{abstract}

\section{Introduction}

\subsection{Research Background}

In contemporary society, people who have good communicative ability are known as having "high emotional intelligence". With the rapid development of society, people need to keep up with the pace of human civilization, and verbal communication is an indispensable element in the development of human civilization, to which euphemism is highly relevant. Euphemism evolved from the language taboos, and it came into being to avoid embarrassment in communication, which provides the semantic feature of indirectness and subtleness for euphemism. Politeness is an essential part in our daily life. In a way, it can represent the degree of human civilization. Thus, verbal euphemism happens to correspond to Leech's Principles of Politeness.

\subsection{Research Significance}

In daily life, it is inevitable for people to communicate with others to achieve certain purpose. The process of communication is one where people seek ideal communicational effect via the use of proper language form. In communication, we need to use euphemism to regulate the conversation to achieve certain alternating goals. Similarly, politeness is also a positive communication strategy which can make language communication successful. This paper argues that the use of euphemism corresponds to Leech's politeness principle and reflects the six maxims of this principle. By relating the use of euphemisms to politeness principle, this paper is restricted to a new angle to look at euphemism and a better understanding of the use of euphemism. At the theoretical level, this paper enlarges the analytical scope of politeness principle and verifies the strong explanatory power of this theory.

\subsection{Literature Review}

Before putting forward politeness principle, many Chinese and foreign linguists and sociologists noticed the phenomenon of politeness and then did many studies on them.

Sociolinguist Goffman proposed the word "face" in 1950. Based on Goffman's face conception, P. Brown and S. Levinson gave more specific description of the face theory. Grice made his contribution 
in this aspect with his Cooperative Principle. However, there still exist some phenomena that can't be explained by this theory. Then, in order to remedy Grice's cooperative principle, after this principle, Leech came up with the politeness principle to rescue the cooperative principle from this serious trouble.

The real pragmatic study of euphemism within the Chinese linguistic circles began in 1980s, since pragmatics was brought into China. The study on politeness could be generally split into two categories: one is based on the domestic culture focusing on the Chinese traditional politeness by applying the foreign theories to meet the changing demands, generally reflected on the explanation of address form and euphemism. The other one is trying to propose the relevant theory by using imported research in this linguistic circle for reference. Chinese politeness study mainly consists of questioning and testing the availability of Leech's politeness principles, making efforts to investigate the features of Chinese politeness thoroughly, and proposing its own Chinese politeness theories. Some scholars have introduced what had been found in the study of politeness in the western countries at that time. $\mathrm{Gu}$ Yueguo and $\mathrm{Xu}$ Shenghuan have combined western politeness theories with Chinese, and made some modifications as well as a lot of achievements.

\section{Relationship Between Euphemism and Politeness Principle}

\subsection{Euphemism and Interpersonal Communication}

Euphemism has been widely applied in human communication and our daily life. It also can be treated as a kind of polite way. Euphemism and taboo have gone through two stages. In traditional society, at almost time, they are used for religious control. In modern English, they often used in unwilling mentioned things, such as salary, body function sex and death. So when people talk about such things, they have to find euphemisms to replace those kinds of direct words and expressions. In order to avoid talking them directly, they often use some indirect language to express them.

\subsection{Euphemism and Politeness Principle}

Showing politeness and respect is the basic social function of euphemism. Politeness principle also implies this function. Euphemisms can make the speakers feel comfortable when talking about objects to which they feel too shy to refer directly. On the other hand, euphemisms are intended to help maintain the hearer's self-image. People usually employ euphemisms in their communication in order to show politeness to the addressee even though they have to violate the cooperative principle.

Therefore, it is reasonable to say that euphemism has something to do with politeness. We can associate the use of euphemism with politeness principle.

\section{Application of Euphemism Under Politeness Principle}

\subsection{Adherence to Tact Maxim}

Tact maxim means to minimize the cost to others in language expressions, which is reflected in the usage of euphemism.

For example:

I saw two drunken gentlemen fighting in the street when I passed by a small village.

As we all know, using "gentlemen" was not so suitable in this example, but here, it is because the word "drunken" had derogatory sense, so in order to adhere to the tact maxim, the speaker decided to use the word "gentlemen". This kind of expression gives people a sense of humor by putting"drunken" and "gentlemen" together. In some way, the euphemistic expression changes the meaning of the sentence and brings an amazing effect.

Let us look at another example:

I'm so sorry the dictionary is needed, but you also can use it till 9 o'clock. Is it convenient for $u$ ?

Here, the speaker wants to express his aim for this conversation, his aim is to let the listener give back his dictionary. If he directly says "give me back the dictionary. I want it." Different expressing will lead to different effect. Maybe because of directly expressing of speaker will make the listener may feel unpleasant. 
To save one's face is one of the purposes of using euphemisms. You must think about not only the feeling of yourself but also the feeling of your partner when you talk something with your partner. Excretion is one of the unpleasant facts of life, and maybe will offend them. Speakers and listeners will feel so embarrassed when mentioning these unpleasant topics in a conversation. Therefore, the creation of a large euphemistic lexicon has been spurred. At the same time, there also come various ways to express the need:

(1) I have to pay a call.

(2) I would like to be excused.

(3) I have to retire for a moment.

(4) Where is the restroom?

(5) May I wash hands?

(6) Do you want to make yourself comfortable?

(7) Have you taken your precautions before the days outing?

It means people have strong desire to get out form barbarism and become civilized creatures by using of euphemisms.

In China, there are also many expressions like these. For example: 我星期三买东西，你借我的 钱星期三之前还给我都可以。

From the above examples, we can know that we can express what we want to say by a roundabout way in order to save other's face. Avoiding making listeners feel uncomfortable, this kind of effect will be much better. Both of speakers and the listeners will benefit from this expressing.

\subsection{Adherence to Generosity Maxim}

Generosity maxim means the speakers minimize benefiting self or maximize cost to self. The use of many euphemisms both in English and Chinese is adhering to generosity maxim. Take the service industry for example, we frequently hear: "What can I do for u, Sir/Madam?" instead of "Do you need me to offer help?" Such kind of expression implies the generosity maxim. In fact, he speaker does not want to get answer form the listener, just in order to achieve the communicative goal in a roundabout way.

Next is another example:

I am still a weak student while Tom becomes a top student after the exam."

In this sentence, the speaker expresses his ideas clearly and adheres to generosity maxim too. A weak student refers to the students who never make any progress in their studies, while top students are the exceptional ones. The speaker tries to minimize benefit of himself in the conversation to show his respect towards Jason. In Chinese, there are similar expressions belonging to this type. For example, a Chinese will say 据说你将要搬到成都的新家了, 老朋友我能否帮上什么忙吗? instead of 据说你将要搬进新家了，需要我帮忙吗?

\subsection{Adherence to Approbation Maxim}

Approbation maxim means that the speaker minimizes dispraise of others but maximizes praise of others. If we are given a good appraisal by others, we will feel be respected and happy, on the contrary, we will fell disrespected or unhappy. Many euphemisms aim to give others highly appraisal, and to minimize dispraise of others. In both languages, there are many corresponding euphemisms adhering to approbation maxim. For example, people will say "You are in some degree distorting the truth." or "You are being uneconomical with the truth." Rather than "You are telling a lie." The aim of teaching is tend to correct student's current behaviors and tell their parents the condition, but teachers need to care about the self-respect of the students, and save parents' face. For this reason, the euphemisms of this kind are often used in such speech context, such as "I think Tom has slow mind in his study." and "I am afraid that he has to work hard on his studies."

In Chinese, there is a similar phenomenon. For example, people prefer to use “后进生, 学习吃 力的学生” rather than “差生” when refer to those academically weak students. All these euphemisms just right reflect approbation maxim. It is clever and wise for the teacher to express his ideas in such a roundabout way. At the same time, students can accept it easily. The use of 
euphemisms which observes approbation maxim not only makes his suggestions easily acceptable to students, but also helps the teacher achieve his communicative purpose. In such specific context, on the one hand the teacher achieves his current aim, on the other hand the students can be encouraged the by using of euphemism, for the euphemism signals to the academically week students that they are not discriminated and given up by the teacher, they still have the potential to become good learners if they put more efforts into their study. Anyway, euphemisms play a big role in helping to make a great success on the education process.

\subsection{Adherence to Modesty Maxim}

Modesty maxim means that the speakers don't praise or avoid praising self. A lot of euphemisms in both English and Chinese adhere to the modesty maxim. Especially in Chinese culture, people always show respect and politeness to others by means of trying best to be modest. On some occasions, people would rather to demean himself to achieve modest effects by using euphemism. The English anti-euphemisms which aim to maximize dispraise and minimize praise are also used for this purpose.

In English, sometimes people will call himself "Your humble servant" . In China, people will call himself “鄙人”, his father “家父”, his daughter “犬女”, his house “寒舍” and his opinion “拙见”, etc. This kind of euphemisms seem to go against the politeness principle of creating euphemisms, but in fact they are hearer-oriented, which means that the speaker hopes the hear can feel his modesty through the use of such euphemistic expressions.

Here is another example:

When people are questioned "Have you ever seen our marriage certificate?", the corresponding answer should be "No, I have not." or "I think I have not." according to English grammar. However, the proper replies could be:

A: Have you guys seen Mr. Wang recently?

B1: I am afraid not.

B2: I do not think I have.

B3: I cannot remember clearly.

These English negation expressions are commonly seen as "thank you very much", "thanks a lot", "I am sorry" and "excuse me but...". Euphemisms adhered to modesty maxim of politeness principle reflect English speakers' psychological cultural accomplishments.

In China, the euphemisms of this kind would be such expressions as in the speech of a lecturer in the opening ceremony

此次任务能够顺利完成归功于各位这一段时间来的付出与辛苦。

这次演讲只能代表我个人的一些拙见，如有不足之处，请大家多多见谅。

\subsection{Adherence to Agreement Maxim}

Agreement maxim means that the speakers try to agree more with others. Under certain circumstances, people cannot always reach agreement on something in the communication, but in most cases they still want to be polite by expressing the ideas indirectly, and try their best to show their different opinions tactfully. The common way of doing this would deliver their different meanings with some specific notions with fuzzy senses. All these measures adhere to the agreement maxim.

Here are the examples:

(1) A: Would you mind teaching me how to make a beautiful PPT.

B: I think Mr. Chen is the better option.

(2) A: Where shall we meet before attending the class? How about in the library?

B: How about Teaching Building NO.6?

(3) A: What is your opinion on this pair of new shoes?

B: They are very fashionable, but I favor the black simple ones.

(4) A: Have you ever seen my presentation on Shakespeare's sonnet?

B: Well, hum, it is very impressive. 
In dialogue (1), when A turns to B for help, B proposes Mr. Chen is the best choice to free himself from the face-threatening act of saying "no" directly to A. In dialogue (2), A gives a suggestion for where they meet, while B gives his own suggestion with a rhetorical question instead of yes or no. In dialogue (3), B seems to agree with A by saying the shoes are fashionable, and then what follows the sentence is the word "but", which is an adversative discourse maker and functions as a signal for his real thought. In dialogue (4), when A asks B for advice, B replies the word "impressive" to cover his real meaning "I did not care about it" or "I actually have not been there". Here B's speech changes the original speech's locutionary act, which means to refer to a subject while meaning another thing. In this manner, the speakers successfully encode their intended meanings by adhering to agreement maxim in the conversation. With common sense and logical inferring ability in hand, the listener could still understand the speaker's deeper meaning or intention and will not feel uncomfortable in the embarrassing situation.

Here is another example. In this dialogue, $\mathrm{A}$ and $\mathrm{B}$ are in a discussion on a complex topic, and firstly A puts forward his own opinion, while B actually cannot agree with him.

A: What is your view towards my advice?

$\mathrm{B}$ : Your view is very interesting.

"Your view is very interesting" actually means "I disagree with u now". The speaker B told a white lie in order to try to maximize the agreement between them. A similar case to this one is that after the presentation of a lecture, the lecturer will receive polite applause after his speech, even though the audience cannot agree with him or even does not enjoy his performance.

In Chinese there is a situation like this:

$\mathrm{A}$ : 请你过来看一眼, 我临摹的这副字画怎么样啊?

B: 嗯, 还行吧。

We can see that this speaker B applies the tactful euphemism “嗯, 还行吧” to express his true feeling “其实就一般般” , because B does not want to hurt A' s feeling and disappoint him. Furthermore, in English culture, people get used to employing euphemisms like this when they cannot reach agreement: first to reply with yes, and then to show his disagreement in a euphemistic way, for example "Yes, you are supposed to be right in that point, but you are not". Another method in this case is to use a negation or negative transfer. Examples of this kind are like "No! I am afraid not" , "Not quite like that." , “Not in that way.” , and “I do not think it is right to...”. While the euphemistic expressions like these in Chinese are: “你所陈述的观点的确有点道理, 但是我们一致认 为・・・, and “也许不完全是这种情况吧?”。

\subsection{Adherence to Sympathy Maxim}

Sympathy maxim means that the speakers show care to others and respect, but maximizes sympathy between oneself and others. There are a large number of euphemisms both in English and Chinese which reflects this maxim, and the most popular one among them are the euphemisms associated with "death". In American hospitals, as a new emerged euphemism, "to check out" means that the patient has left the hospital, just like the check-out we do in the hotel. With these kinds of euphemism people tend to show the sympathy for the dead and their families, in order to reduce the degree of family members' sadness caused by the leave of their beloved one.

Besides, euphemisms connecting with sympathy maxim are also widely used in the talking about other sensitive topics, such as sex, body functions, disease and so on. When people have to mention these topics, they will take other's feelings into consideration, and show their sympathy to the hearers with euphemistic expressions. For example, in English, "AIDS" is called "social disease"; "butcher" in market becomes "meat technologist"; "housewife" is called "domestic engineer"; "mental defect" is euphemized as “intellectually challenged”. In Chinese, “残疾人教育” is “特殊教育”; “艾滋病” is also called “传染性疾病”; “清洁工人” becomes “城市卫生形象大使”; “丰满” sounds better than “胖”. 


\subsection{Adherence to Sympathy Maxim}

Based on the detailed analysis of the application of euphemism, it is easy to conclude that politeness principle, as an important linguistic theory, lays the foundation of the generation and development of euphemisms in language. No matter in English or Chinese euphemism, "politeness" is so important factor, which is intended to avoid embarrassment and achieve agreement between the two parties in the conversation. Euphemism is definitely an ideal manifestation of politeness principle, and the application of euphemisms on various occasions stands in close relationship with the maxims of politeness principle.

\subsection{Adherence to Sympathy Maxim}

Despite of the above mentioned discoveries in this study, certain limits exist within this research. On the one hand, the linguistic data collected in this paper is rather limited in amount. On the other hand, considering the writer's present grasp of the theory essence and analytical ability, there may be some shortcomings in the analysis. It is hoped that the forthcoming researchers can find good solutions to deal with the limits of this paper.

Euphemism that accords with politeness principle oils human communication. If we can make good use of this language form, human communication will be greatly facilitated and people's interpersonal relations will be more harmonious.

\section{Conclusion}

On the basis of the research results of predecessors, this thesis mainly explores the effective use of English and Chinese euphemisms in the light of politeness principle.

In terms of the relationship between politeness principle and euphemisms, it is not so difficult to find that the speakers try their best to offer convenience to others, but for the speakers themselves, they suffer losses in order to leave good impressions and at the same time make others feel respected.

\section{References}

[1]. Enright, D.J. Fair of Speech: The Uses of Euphemism [M]. Oxford: Oxford University Press, 1985.

[2]. Jary, M. "Relevance Theory and the communication of politeness" [J]. Journal of Pragmatics, 1998(30):27-30.

[3]. Kramsch, Claire. Language and Culture [M]. Shanghai: Shanghai Foreign Language and Education Press, 2000.

[4]. Maglone, M. S. Batchelor. J. A. "Look out for Number One", "Euphemism and Face" [J]. Journal of Communication, 2003.

[5]. Neaman, J. S \& C. G. Silver. kind words: A Thesaurus of Euphemisms[M]. New York: Facts on file, inc. Word Publishing Crop, 1990. 